\title{
Central core disease
}

\section{A correlated genetic, histochemical, ultramicroscopic, and biochemical study}

\author{
HYAM ISAACS, J. J. A. HEFFRON, AND MARGARET BADENHORST \\ From the Clinical Neuromuscular Research Laboratory, Department of Physiology, \\ and the Department of Physiological Chemistry, University of Witwatersrand Medical School, Johannesburg, \\ South Africa
}

SYNOPSIS Two patients suffering from central core disease are presented. The condition is associated with musculoskeletal abnormalities which have been traced back over five generations. In addition to the typical histochemical findings, electronmicroscopic study has revealed the presence of both structured and non-structured cores in adjacent areas. The calcium uptake by the sarcoplasmic reticulum was reduced to one-third of normal. Phosphorylase activity was normal in the one case and reduced to $63 \%$ in the other. Actomyosin $\mathrm{Mg}^{2+}$-activated ATPase activity was decreased, as was the $\mathrm{Ca}^{2+}$-dependent ATPase of the sarcoplasmic reticulum.

Various members of the family presented in this paper have suffered from a variety of musculoskeletal abnormalities. A father and daughter have been studied in detail and suffer from central core disease. Central core disease was first described by Shy and Magee (1956). The biochemical aberrations occurring in the skeletal muscle fibres were first described by Engel et al. (1961). In addition to histochemistry and electronmicroscopy, we have examined the activities of phosphorylase and succinic dehydrogenase in whole homogenates and, also, actomyosin $\mathrm{Mg}^{2+}$. activated adenosinetriphosphate (ATPase) and calcium uptake and ATP activity of sarcoplasmic reticulum (SR) which are indicators of the functional integrity of the contractile and relaxing systems of the muscle fibre and are also a guide to the changes in fibre type occurring in diseased muscle.

\section{CASE 1}

Mr E.A.M., aged 42 years, developed muscular weakness in early childhood involving the legs and particularly noticeable with dorsiflexion of the ankles. The condition has been very slowly pro-

(Accepted 9 June 1975.) gressive over the past 15 years so that some involvement of the more proximal muscles of the lower extremities and back has become obvious. He now has difficulty in climbing stairs and getting out of a chair without the assistance of his arms. There is no complaint of any sensory disturbance. The patient is of above normal intelligence. There is a family history of muscular weakness and musculoskeletal deformities which manifest largely as dropped foot, kyphoscoliosis, and pes cavus. The patient is one of six siblings, two of which are similarly affected.

Examination revealed slight weakness of the proximal muscles of the upper extremities and weakness of the muscles acting about the pelvis. Wasting was most pronounced in the lower extremities where foot drop was prominent. All tendon reflexes were absent. There was no evidence of any sensory abnormality or of incoordination. The cranial nerves and central nervous system were normal.

Electromyography revealed considerable increase in polyphasic motor unit activity. Most of the polyphasic activity was of long duration and increased voltage, but scattered areas of low voltage polyphasic motor unit potentials were also encountered. There was no evidence of denervation activity at the time of testing. Nerve conduction studies revealed velocities of $56 \mathrm{~m} / \mathrm{s}$ motor, $59 \mathrm{~m} / \mathrm{s}$ sensory for the median nerve, and $52 \mathrm{~m} / \mathrm{s}$ motor for the right medial popliteal nerve. 
CASE 2

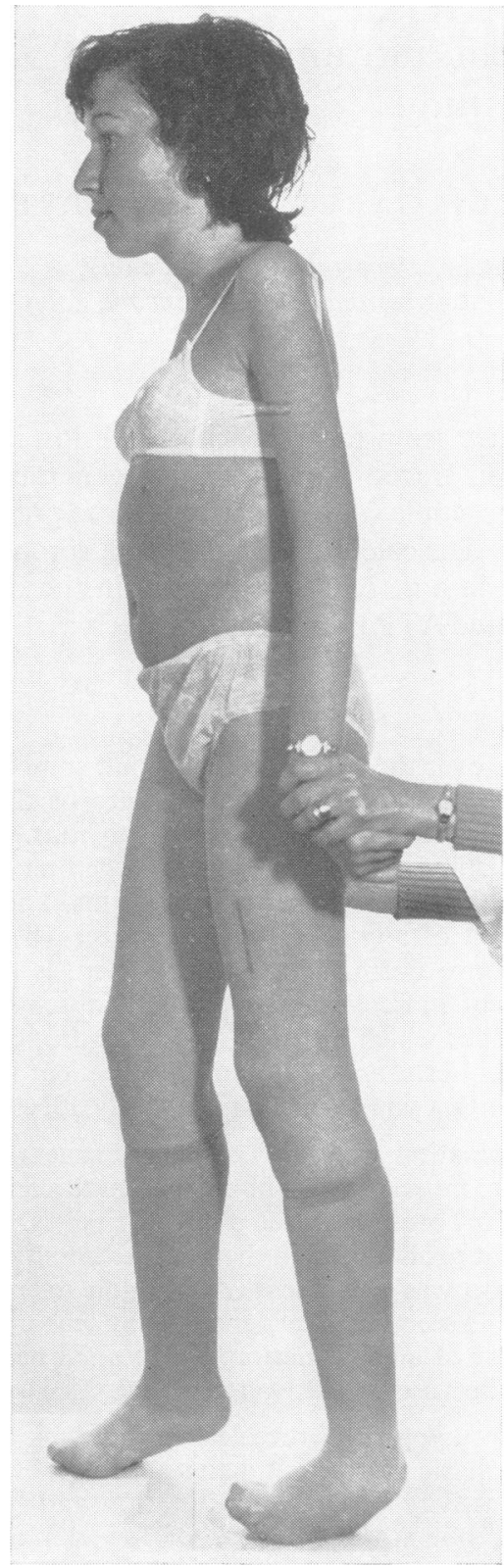

FIG. 1 Case 2. Some of the musculoskeletal abnormalities.
Miss Y.M. (Fig. 1), aged 14 years, daughter of case 1, has been physically weak from the time of birth. Over the past 10 years peripheral deformities have developed so that at the present time she has bilateral pes cavus and foot drop which is most marked on the right side. She has also developed marked kyphoscoliosis and has recently been fitted with a Milwaukee brace. She is unable to run or jump or get up from the lying position. The weakness is generalized but the peripheral muscles are most affected.

On examination, there was evidence of generalized muscular weakness and the tendon jerks were absent. There was no evidence of incoordination and sensation was intact. The tongue appeared somewhat thinner than normal but moved well, and there was no evidence of fasciculation. The cranial nerves were normal.

Electromyography showed evidence of increased polyphasic motor unit potentials of high amplitude and increased duration in most of the muscles and particularly in the distal muscles of the lower extremities where marked fall out of motor unit activity was obvious. There was no evidence of denervation activity at the time of testing. The left lateral popliteal nerve conduction velocity was $\mathbf{5 0}$ $\mathrm{m} / \mathrm{s}$, the right median nerve conduction velocity $57 \mathrm{~m} / \mathrm{s}$, motor and $59 \mathrm{~m} / \mathrm{s}$ sensory.

SPECIAL INVESTIGATIONS Full blood count, blood metabolic and endocrine studies were normal in both cases.

The physical abnormalities in this family were traced back over five generations (Fig. 2). The family originated in Russia.

In case 1 , muscle tissue was removed under local anaesthesia from the peroneus brevis muscle and in case 2 under general anaesthesia from the vastus lateralis muscle. Specimens were removed for routine histology, histochemistry, nerve terminal, end plate, electronmicroscopy, and biochemical study. The fresh frozen sections for histology were stained with haematoxylin and eosin ( $\mathrm{H}$ and $\mathrm{E})$ and a modified trichrome stain (Engel and Cunningham, 1963). The histochemical processes included NAD diaphorase, succinic dehydrogenase, phosphorylase, ATPase pH 9.5, and ATPase pH 4.5 previously treated with EDTA. The motor nerve terminals and end-plates were processed by a modified Ranvier method.

The muscle for biochemical analysis was compared with biopsy samples of the same muscles from three normal individuals. Succinic dehydrogenase (SDH) activity was determined on a whole muscle homogenate prepared in 100 volumes of $0.1 \mathrm{M}$ phosphate buffer pH 7.4. The SDH assay medium 


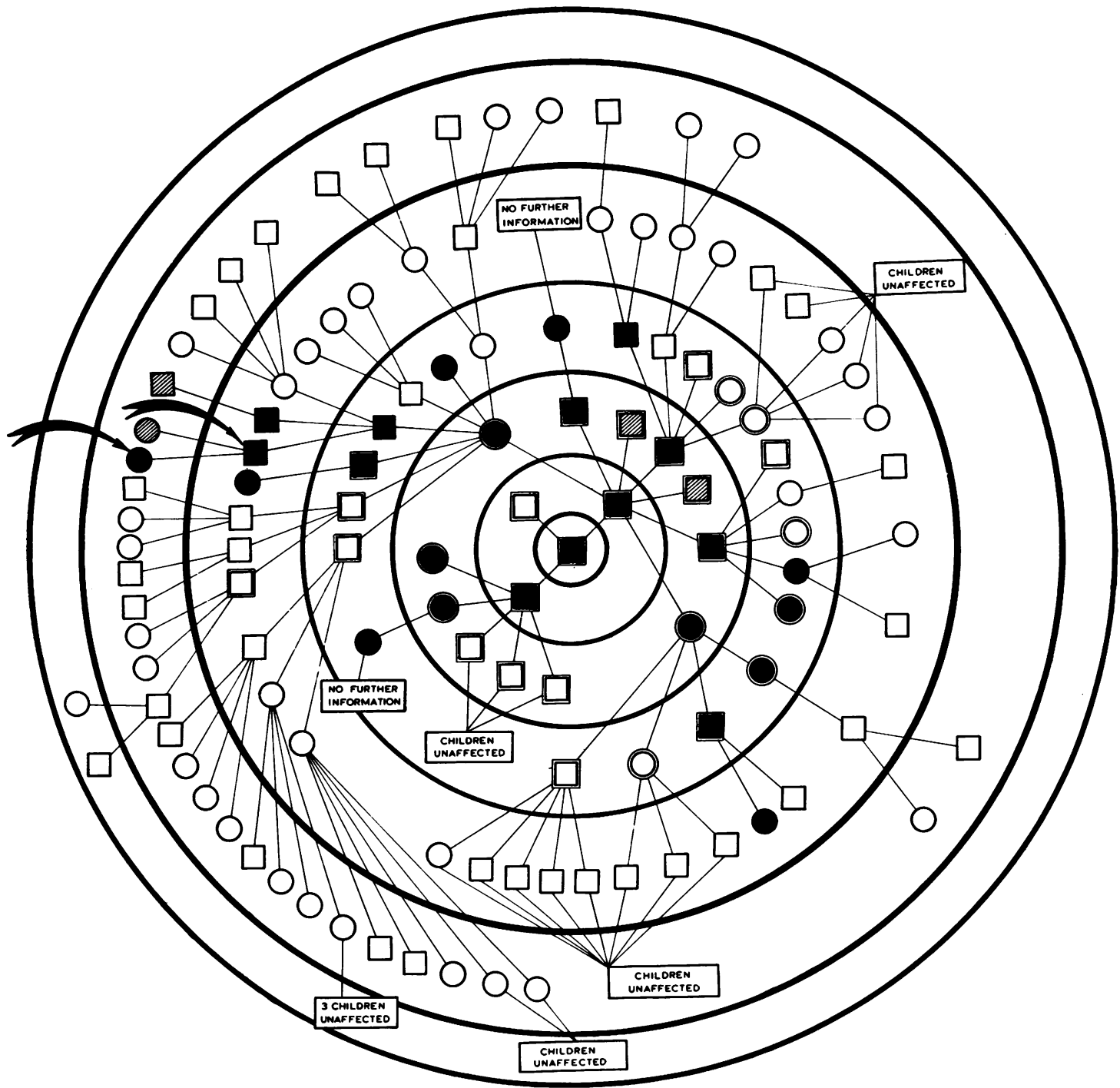

FIG. 2 The familial occurrence of the musculoskeletal deformities demonstrating autosomal dominance. Key: - Affected. $\bigcirc$ Unaffected. Uncertain. $\bigcirc$ Female. $\square$ Male. () Deceased.

contained $50 \mathrm{mM}$ sodium succinate, $0.05 \% p$ iodinitrotetrazolium (INT), and $0.1 \mathrm{M}$ phosphate buffer, pH 7.4. The reaction was terminated with trichloroacetic acid at a final concentration of $5 \%$. The diformazan (reduced INT) was extracted into ethyl acetate and measured spectrophotometrically at $490 \mathrm{~nm}$. A standard curve was prepared with pure diformazan in ethyl acetate. SDH activity is expressed as $\mu \mathrm{mol}$ diformazan per gram tissue wet mass per minute at $30^{\circ} \mathrm{C}$. Phosphorylase activity in the whole homogenate was measured in the direction of glycogen synthesis at $30^{\circ} \mathrm{C}$, as previously described by Isaacs and Heffron (1975a). Sarcoplasmic reticulum was prepared in $0.3 \mathrm{M}$ sucrose-20 $\mathrm{mM}$ imidazole $\mathrm{pH} \quad 6.85$ as already described by Isaacs and Heffron (1975b). Actomyosin was extracted from the $2000 \mathrm{~g}$ pellet (Isaacs and Heffron, 1975b). SR was obtained by centrifuging the postmitochondrial supernatant at $200,000 \mathrm{~g}$ for 60 minutes at $0^{\circ} \mathrm{C}$. ATPase activity and Ca-uptake of 


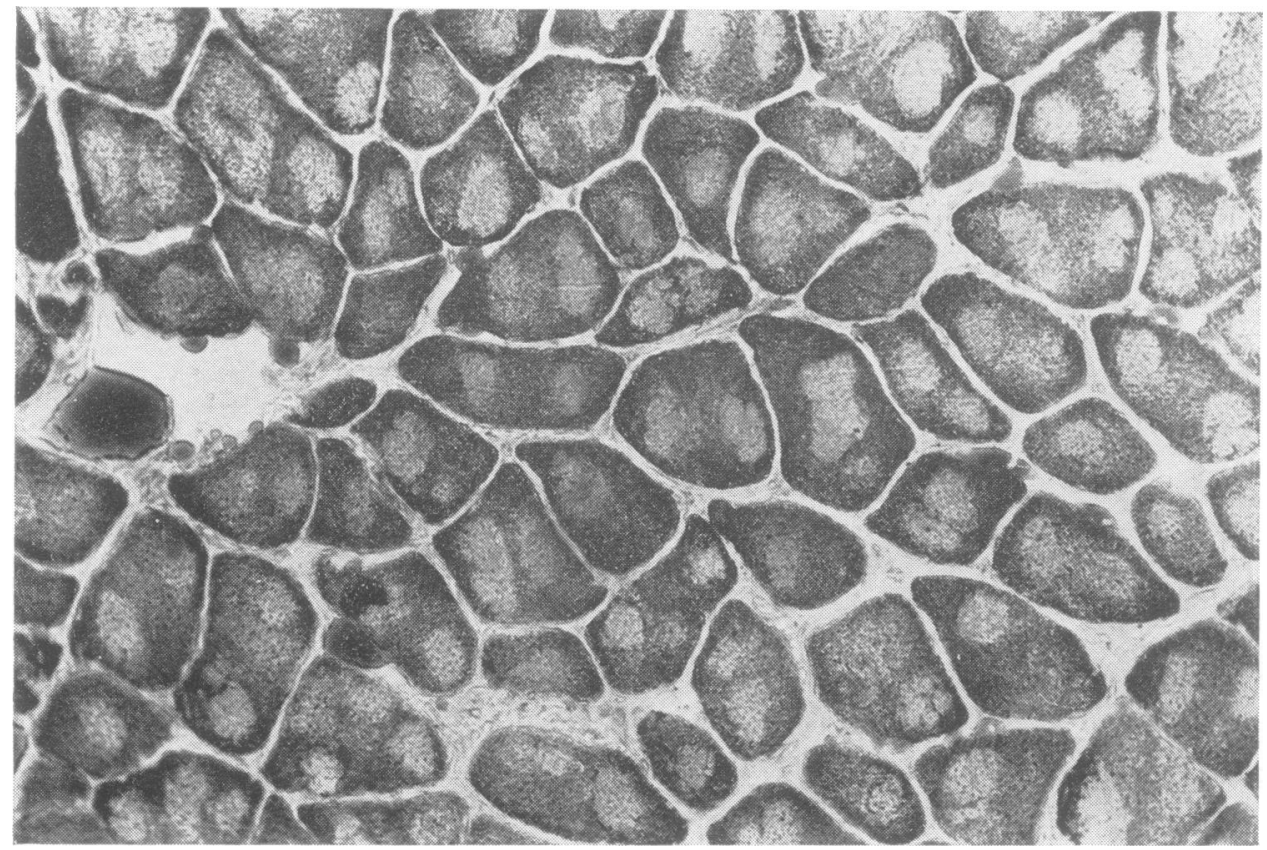

FIG. 3 NAD diaphorase preparation illustrating the core formation and the absence of type 2 fibres. $\times 50$.

the SR were measured in the following medium: $5 \mathrm{mM}$ ATP-tris, $5 \mathrm{mM} \mathrm{MgCl}_{2}, 100 \mathrm{mM} \mathrm{KCl}, 5 \mathrm{mM}$ potassium oxalate, $20 \mathrm{mM}$ imidazole- $\mathrm{HCl}, \mathrm{pH}$ 6.85, and $0.1 \mathrm{mM}{ }^{45} \mathrm{CaCl}_{2}$ (ca $0.5 \mu \mathrm{C} / \mathrm{ml}$.). 'Basal' ATPase activity of the SR was determined in a similar medium, except that calcium was omitted and $1 \mathrm{mM}$ ethylene (bis-glycoe-B-aminoethylether) $-\mathrm{N}^{\prime}, \mathrm{N}^{\prime}$-tetraacetic acid (EGTA) was included to chelate free calcium in the medium. $\mathrm{Ca}^{2+}$-dependent ATPase activity was obtained by subtracting the 'basal' activity from the total. Further details of the assay procedures for ATPase activity and Ca-uptake have already been published (Isaacs and Heffron, 1975b). $\mathrm{Mg}^{2+}$-activated ATPase activity of actomyosin was measured as already described (Isaacs and Heffron, 1975b). Protein in the fractions was determined by the method of Lowry et al. (1951). All assays were carried out in duplicate. Analytical grade chemicals, supplied by British Drug Houses Ltd., U.K., and Sigma Chemical Company, St Louis, U.S.A., were used throughout and solutions were made up in glass-double distilled water. ${ }^{45} \mathrm{CaCl}_{2}$ was obtained from the Radiochemical Centre, Amersham, U.K.

Alkali soluble protein in small pieces of the biopsies from five normal patients and from the father was determined by the biuret method after solubilization of the protein in $3.0 \mathrm{ml}$ of $0.05 \mathrm{~N} \mathrm{NaOH}$ for $18-20$ hours (Lilienthal et al., 1950). In the case of the daughter, insufficient material was available for this determination. However, any visible fat was dissected free before weighing and homogenization of the muscle for enzyme studies.

In view of the correlation between central core disease and malignant hyperthermia (Denborough et al., 1973; Dubowitz, 1974; Isaacs and Barlow, 1974), we tested a muscle biopsy from the father for susceptibility to malignant hyperthermia using the halothane contracture test of Ellis et al. (1972). A strip of muscle (ca $2 \mathrm{~cm}$ long and $0.3 \mathrm{~cm}$ diameter) was attached to two stimulating electrodes in a muscle bath containing Ringer phosphate (pH 7.3) at $37^{\circ} \mathrm{C}$. Tension was recorded with a Statham UC 3 force transducer and displayed on a Beckman Dynograph physiological recorder. As soon as the muscle was obtained from the operating theatre its viability was checked by direct stimulation. After this, halothane $(3.2 \%)$ was introduced into the Ringer solution using a calibrated Fluotec Mk II vaporizer and an oxygen flow rate of 1.5-2.0 litres per minute. No halothane-induced contracture was observed, even when the recorder was set to a fullscale sensitivity of $500 \mathrm{mg}$ and monitored for 30 minutes after introduction of the anaesthetic. 


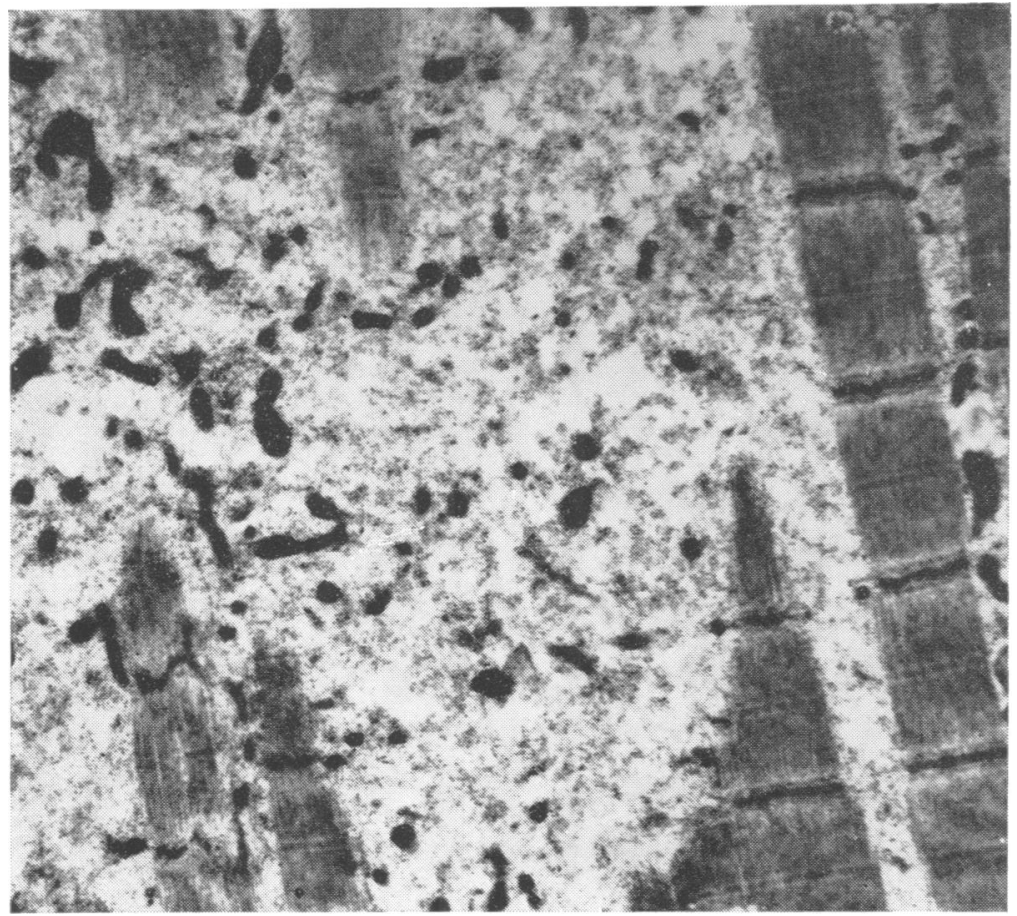

FIG. 4 Fine structure of muscle illustrating an area of total loss of myofibrils and mitochondria. $\times 8000$.

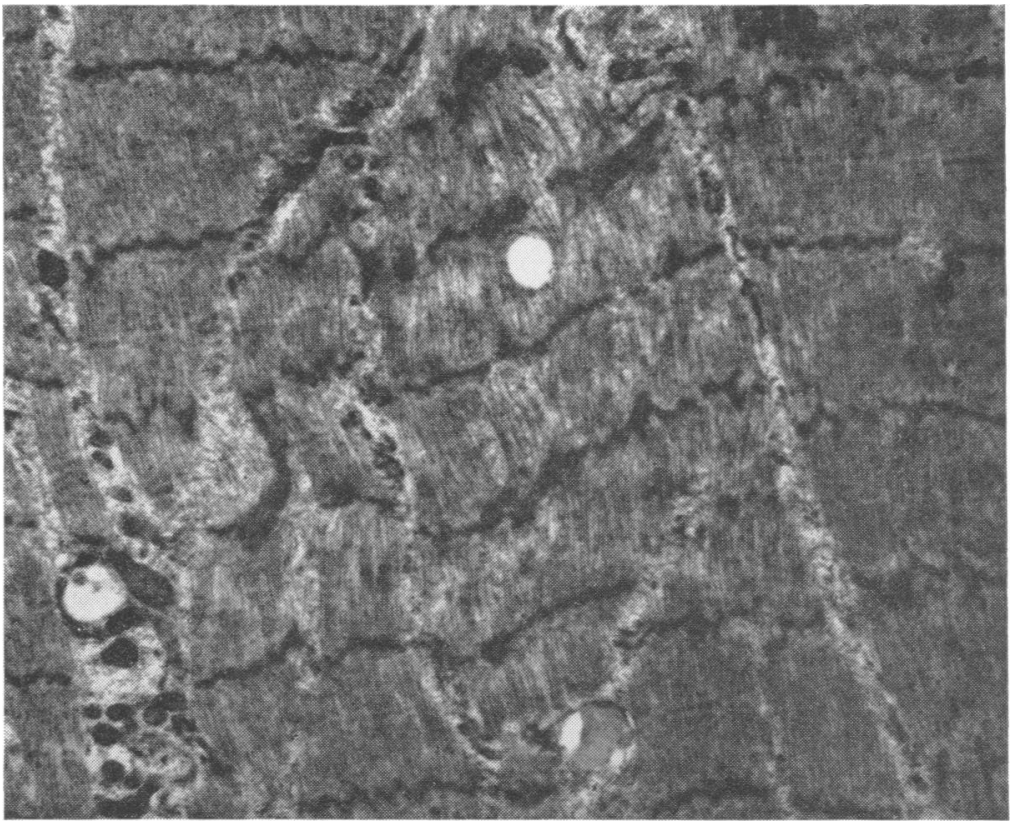

FIG. 5 Fine structure of muscle illustrating an area of $Z$ line streaming (structured core).$\times 12000$. 


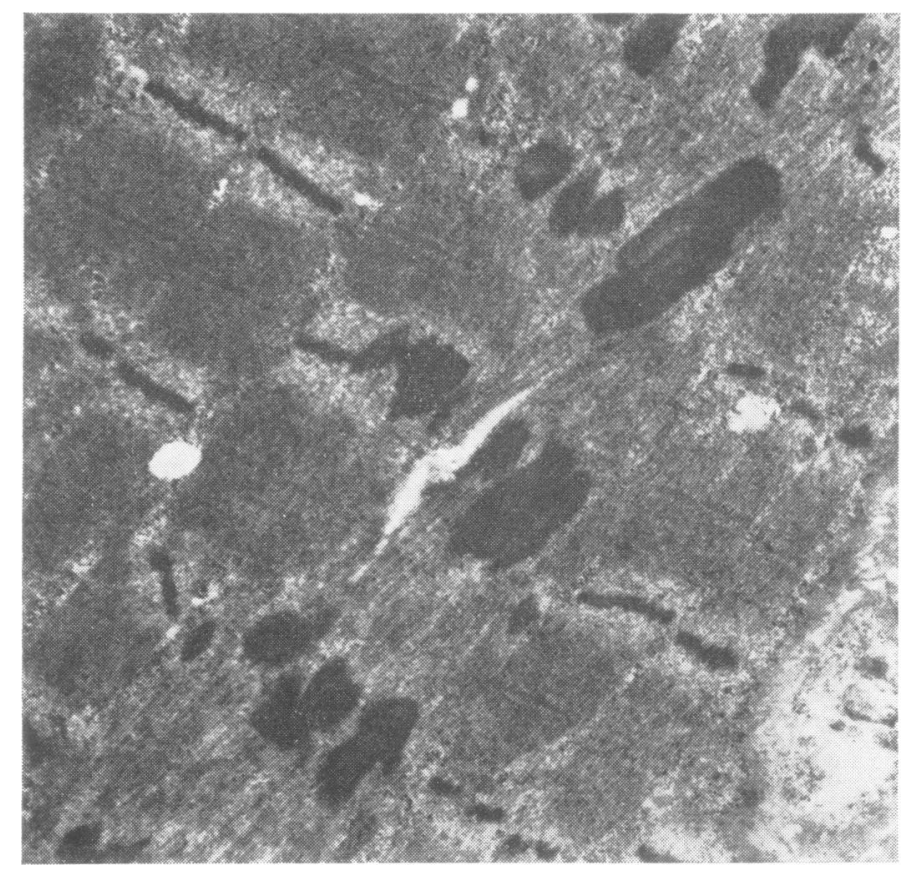

FIG. 6 Fine structure of muscle illustrating rod-like structures in an area of disintegration. $\times 10000$.

\section{RESULTS}

The genetic study, based on the various physical abnormalities, confirmed the autosomal dominant inheritance of this disease (Fig. 2).

The histology of the muscle taken from Case 1 revealed a marked variation in fibre size $(80$ $140 \mu \mathrm{m})$. Fibrous and fatty tissue were present in increased amounts. The trichrome stain showed no evidence of ragged red fibres or nemaline rod formation. Histochemical study revealed that the muscle fibres were almost entirely type 1 . The fibres showed evidence of extensive core formation which in longitudinal sections were seen to extend throughout the length of the fibre. The cores are particularly well seen in the NAD diaphorase stain (Fig. 3) and varied from 1-6/fibre. The histology and histochemistry of case 2 was much the same as that of case 1 , with fibre size varying between 80-140 $\mu \mathrm{m}$.

The nerve terminal and end-plate study revealed excessive terminal branching with a terminal innervation ratio of $1: 32$ (normal $1: 25$ ) (Coërs et al., 1973). The end-plates in many in- stances were underdeveloped and ended in a single bulb-like expansion.

Electronmicroscopic study, similar in both cases, revealed scattered areas where total loss of myofibrillar structure had occurred. In other areas blurring and streaming of the $Z$ lines were encountered (Fig. 4). In the unstructured core areas no mitochondria were found, but remnants of $\mathrm{T}$ tubules and sarcoplasmic reticulum were seen (Fig. 5). Scattered in some areas of disintegration were rod-like structures (Fig. 6).

The activities of the various enzymes and the rate and extent of calcium uptake by the SR are presented in the Table. SDH activity in both cases was about one-third of the mean in normal muscle. Phosphorylase activity in the muscle of the daughter was in the normal range, though it was reduced by $63 \%$ in the father. Actomyosin $\mathrm{Mg}^{2+}$-activated ATPase activity was decreased by $50-60 \%$ in both cases. $\mathrm{Ca}^{2+}$-dependent ATPase activity of the SR was reduced by $49 \%$ and $63 \%$ in the father and daughter respectively.

The corresponding changes in the rate and extent of calcium uptake were $76 \%$ and $69 \%$ in the father, and $88 \%$ and $84 \%$ in the daughter. 
TABLE

MUSCLE ENZYME ACTIVITIES AND RELATED DATA IN CENTRAL CORE DISEASE

\begin{tabular}{|c|c|c|c|}
\hline & \multicolumn{2}{|c|}{ Central core disease } & \multirow[t]{2}{*}{ Normal $^{*}$} \\
\hline & Case 1 & Case 2 & \\
\hline $\begin{array}{l}\text { 1. Succinic dehydrogenase: } \\
\left(\left(\mu \mathrm{mol} \text { diformazan } / \mathrm{g} / \mathrm{min}, 30^{\circ} \mathrm{C}\right)\right.\end{array}$ & 0.320 & 0.370 & $0.984 \pm 0.117(4)$ \\
\hline $\begin{array}{l}\text { 2. Phosphorylase: } \\
\left(\mu \mathrm{mol} \mathrm{Pi} / \mathrm{g} / \mathrm{min}, 30^{\circ} \mathrm{C}\right)\end{array}$ & 20.5 & 47.2 & $55.3 \pm 3.0$ \\
\hline $\begin{array}{l}\text { 3. } \mathrm{Mg}^{2+} \text {-activated actomyosin ATPase: } \\
\left(\mu \mathrm{mol} \mathrm{Pi} / \mathrm{mg} \text { protein/min, } 30^{\circ} \mathrm{C}\right) \\
\text { 4. } \mathrm{SR} \mathrm{Ca}^{2+} \mathrm{Ca}^{2} \text { dependent ATPase: }\end{array}$ & 0.120 & 0.143 & $0.239 \pm 0.017$ \\
\hline 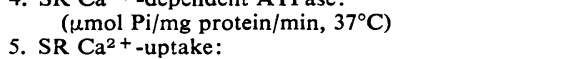 & 0.346 & 0.252 & $0.676 \pm 0.021(3)$ \\
\hline 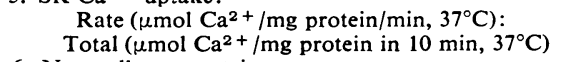 & $\begin{array}{l}0.192 \\
0.598\end{array}$ & $\begin{array}{l}0.094 \\
0.306\end{array}$ & $\begin{array}{l}0.790 \pm 0.049(3) \\
1.958 \pm 0.103(3)\end{array}$ \\
\hline $\begin{array}{l}\text { 6. Non-collagen protein: } \\
\text { (mg/gram muscle, wet weight) }\end{array}$ & 178.5 & - & $198.3 \pm 4.2$ \\
\hline
\end{tabular}

* Data for normal muscle are given as mean \pm SEM. Number of observations in parentheses.

The non-collagen protein in the muscle of the father was $178.5 \mathrm{mg}$ per gram of muscle, wet weight, compared with a normal value of $198.3 \pm$ $4.2(\mathrm{SEM}, \mathrm{N}=8)$.

\section{DISCUSSION}

Central core disease is, in the vast majority of cases, inherited as an autosomal dominant trait (Shy and Magee, 1956; Dubowitz and Roy, 1970). Occasionally, it seems that the condition may be present in an autosomal recessive abnormality (Dubowitz and Platts, 1965) and may also occur sporadically (Engel et al., 1961; Bethlem et al., 1971). The condition has also been described as one of the myopathies found in individuals susceptible to malignant hyperpyrexia (Denborough et al., 1973; Isaacs and Barlow, 1974). The cores in these earlier cases were much less extensive and, as opposed to the cores seen in the present cases, did not extend so extensively through the length of the fibre and in this respect resembled a severe example of target fibre formation. In the family presented in this paper the disease could be traced back over five generations and the dominant nature of inheritance established.

Clinically, the patient with central core disease present with muscular weakness, hypotonia, and various skeletal deformities. The muscle weakness is usually most marked in the pelvic region, while the proximal muscles of the shoulder girdle are involved but to a lesser extent. The ocular muscles are normal, the patients are of normal intelligence, and sensation and coordination are normal. In the present family, weakness of dorsiflexion of the feet is a prominent feature. Shortening of the tendo achillis was also quite marked in case 2, producing a pes equinovarus deformity. Severe kyphoscoliosis was present. Most of the involved members of this family presented with these deformities in a lesser or more severe form. The relatively minor proximal upper limb weakness and the typical muscle histochemistry distinguish this disorder from the scapuloperoneal syndrome.

The frequency of pes cavus and kyphoscoliosis in association with central core disease has been commented on (Afifi et al., 1965; Gonatas et al., 1965, Armstrong et al., 1971). Similar deformities have also been noted in certain families susceptible to malignant hyperpyrexia (Isaacs and Barlow, 1974).

The cores occur in the type 1 fibres and vary between one and six in some fibres, and they are best seen with the oxidative enzyme stains. In the present cases, the muscle was composed almost entirely of type 1 fibres. This has been found in a few previously reported cases (Dubowitz and Pearse, 1960; Gonatas et al., 1965; Mittelbach and Pongratz, 1968). The disappearance of type 2 fibres produces an altered ratio between type 1 and 2 fibres, suggests that the type 2 fibres are severely affected in this disorder, and 
jmplies that a major disturbance of type 2 motor neurones exists in this disease. The preponderance of type 1 fibres might alternatively suggest some arrest in development in embryonic life, but the evidence is more in favour of a progressive loss of type 2 fibres, as the less severely involved muscles still contain some type 2 fibres as established by subsequent biopsy of the deltoid muscle in case 1 .

The ultrastructural appearance of the muscle was similar to the earlier observations of Engel et al. (1961), Dubowitz and Roy (1970), and Telerman-Toppet et al. (1973). The core areas showed varying degrees of disorganization. In some areas, the abnormality was seen as shortening of the sarcomeres in the core area, while in other areas there was marked loss of myofibrils, loss of mitochondria, with relative preservation of $\mathrm{T}$ system. Rods were observed in both cases, an observation which was described by Afifi et al. (1965). These authors suggested that nemaline myopathy and central core disease may be different manifestations of the same disease; both show a progressive loss of type 2 fibres. In another case of malignant hyperpyrexia (Isaacs and Barlow, 1974), rod-like structures were also found. Telerman-Toppet et al. (1973) found rod-shaped bodies in one atrophic fibre. Karpati et al. (1971) described a fatal case of nemaline myopathy in which cores or target fibres and rods were found in the diaphragmatic muscle. A further association between rods and cores occurs as a manifestation of the pathological change after tenotomy (Engel et al., 1966; Shafiq et al., 1969). There is also a positive relationship between target fibres, targetoid fibres, and central cores; all imply denervation or loss of 'trophic' neuronal activity.

In the present cases, there was a good correlation between the morphological and biochemical findings. The large decrease in mitochondrial content, measured as maximal SDH activity in the muscle homogenates, supports the electron microscopic findings of reduced numbers of mitochondria. This result is in sharp contrast with the situation in familial myopathies characterized by ragged-red muscle fibres in which the mitochondrial mass is greatly increased (Kark et al., 1973). The finding of rededuced phosphorylase activity in the muscle of the father, compared with that of the daughter, is difficult to explain. Further, a decrease in phosphorylase activity is in keeping with the histochemical studies, which showed a predominant type 1 fibre composition. Our results are at variance with those of Engel et al. (1961) who were unable to detect phosphorylase activity in a case of central core disease. The decrease in actomyosin $\mathbf{M g}^{2+}$-activated ATPase activity is again consistent with the presence of mainly type 1 fibres in the diseased muscle. If the activities of SDH and phosphorylase be expressed in terms of the non-collagen protein content, rather than on a wet tissue mass basis, the activities are increased slightly, since the noncollagen protein in the single case examined was decreased by $10 \%$ compared with normal muscle levels. Laudahn and Heyck (1965), in a study of progressive muscular dystrophy, correlated enzyme activity changes with the stage of severity of the disease assessed histologically. They observed that certain enzymes-for example, isocitric dehydrogenase, phosphoglucose isomerase-showed an initial increase followed by a later decrease. Applying this to phosphorylase activity in central core disease would explain the observed difference between father and daughter in the present study and possibly the finding also of Engel et al. (1961).

The large reduction in $\mathrm{Ca}^{2+}$-dependent ATPase activity of sarcoplasmic reticulum and in the rate and extent of calcium uptake indicates extensive atrophy of the sarcoplasmic reticulum. Although reductions in ATPase activity and calcium uptake have been observed in several myopathies (Samaha and Gergely, 1969; Britt and Kalow, 1970; Isaacs and Heffron, 1975b), the reductions were not so marked as in the present case of central core disease. In Duchenne type muscular dystrophy (Samaha and Gergely, 1969) and in malignant hyperpyrexia (Isaacs and Heffron, 1975b), SR ATPase activity and the rate of calcium uptake are reduced proportionately. The concept of efficiency for expressing the coupling of energy through ATPase activity with calcium uptake transport mechanism was introduced by Samaha and Gergely (1969) and is expressed as the rate of calcium uptake/rate of ATPase activity. In Duchenne muscular dystrophy and malignant hyperpyrexia the efficiency remains normal, though the absolute activities are reduced. In central core disease, both the 
efficiency and absolute activities are apparently decreased suggesting uncoupling of calcium transport and ATPase activity, together with a transition to a slow fibre type. It is known that in the slow fibres of laboratory animals, such as the rat, the rate and extent of calcium uptake is about one-fifth the values in fast fibres (Streter, 1969; Margreth et al., 1972). Although no equivalent data are available for slow and fast fibresthat is, type 1 and 2 -in man, it is reasonable at this stage to conclude that the reduction in SR ATPase activity and calcium uptake are due to the disappearance of type 2 fibres in central core disease. This is in substantial agreement with the histochemical finding of only type I fibres in the disease.

Margreth et al. (1972), in a study of the effects of experimental denervation on SR function from slow and fast muscles of the rat, found that, after one week of denervation, SR ATPase activity and calcium uptake increased significantly, while these activities fell slightly in fast muscle SR. These results are in keeping with the responses of other muscle functions to denervation, and it is reasonable to conclude that SR ATPase and calcium uptake will decrease after prolonged periods of denervation. The decrease in calcium uptake observed in the two cases of central core disease is likely to be a consequence of denervation.

The low $\mathrm{Ca}^{++}$uptake by the $\mathrm{SR}$ is a feature not yet described in central core disease. This finding provides yet another non-specific feature in common between malignant hyperpyrexia and central core disease. Britt and Kalow (1970) consider the SR defect as a major factor in the initiation of the heat production in malignant hyperpyrexia and the finding of very low uptake in central core disease suggested that these patients should be examined to determine their susceptibility to malignant hyperpyrexia by the muscle strip exposure technique outlined by Ellis. There is no history of malignant hyperpyrexia in this family (but susceptibility or otherwise must be established, as they are frequently subjected to orthopaedic corrective procedures). In the case of the father, exposure of a muscle strip to halothane did not produce contracture. This suggests that the reduced calcium uptake by SR from patients with malignant hyperpyrexia may not be the important triggering factor in the malignant hyperpyrexia syndrome but may, in fact, be due to a denervating process as observed here in central core disease.

We further suggest that all future work on SR calcium uptake be considered in terms of the fibre type population.

This work was made possible by grants from the S.A. Medical Research Council, the University of Witwatersrand Council's Faculty of Medicine Research, the National Council for the Care of Cripples, and the Atomic Energy Board of South Africa.

\section{REFERENCES}

Afifi, A. K., Smith, J. W., and Zellweger, H. (1965). Congenital non-progressive myopathy. Central core disease and nemaline myopathy in one family. Neurology (Minneap.), 15, 371-381.

Armstrong, R. M., Koenisgberger, R., Mellinger, J., and Lovelace, R. E. (1971). Central core disease with congenital hip dislocation. Study of two families. Neurology (Minneap.), 21, 369-376.

Bethlem, J., van Wijngaarden, G. K., Meijer, A. E. P., and Fleury, P. (1971). Observations on central core disease. Journal of the Neurological Sciences, 14, 293-299.

Britt, B. A., and Kalow. W. (1970). Malignant hyperthermia: aetiology unknown. Canadian Anaesthetists Society Journal, 17, 316-339.

Coërs, C., Reske-Nielson, E., and Harmsen, A. (1973). The pattern of terminal motor innervation in healthy young adults. Journal of Neurological Sciences, 19, 351-356.

Denborough, M. A., Dennett, X., and Anderson, R. M. D. (1973). Central core disease and malignant hyperpyrexia. British Medical Journal, 1, 272-274.

Dubowitz, V. (1974). Personal communication.

Dubowitz, V., and Pearse, A. G. E. (1960). Oxidative enzymes and phosphorylase in central core disease of muscle. Lancet, 2, 23-24.

Dubowitz, V., and Platts, M. (1965). Central core disease of muscle with focal wasting. Journal of Neurology, Neurosurgery, and Psychiatry, 28, 432-437.

Dubowitz, V., and Roy, S. (1970). Central core disease of muscle. Clinical, histochemical and electron microscopic studies of an affected mother and child. Brain, 93, 133-146.

Ellis, F. R., Keaney, N. P., Harriman, D. G. F., Sumner, D. W., Kyei-Mensah, E., Tyrell, J. H., Hargreaves, J. B., Parikh, J. H., and Mulrooney, P. L. (1972). Screening for malignant hyperpyrexia. British Medical Journal, 5, 559-562.

Engel, W. K., Brooke, M. H., and Nelson, Ph. G (1966). Histochemical studies of denervated or tenotomized cat muscle: Illustrating difficulties in relating experimental animal conditions to human neuro-muscular diseases. Annals of the New York Academy of Sciences, 138, 160185.

Engel, W. K., and Cunningham, G. C. (1963). Rapid examination of muscle tissue, an improved trichrome method for fresh-frozen biopsy sections. Neurology (Minneap.), 13, 919-923.

Engel, W. K, Foster, J. B., Hughes, B. P., Huxley, H. E., and Mahler, R (1961). Central core disease. An investigation of a rare muscle cell abnormality. Brain, 84, 167-185.

Gonatas, N K , Perez, M. C., Shy, G M., and Evangelista, I. (1965). Central 'core' disease of skeletal muscle. Ultra- 
structural and cytochemical observations in two cases. American Journal of Pathology, 57, 503-524.

Isaacs, H., and Barlow, M. B. (1974). Central core disease associated with elevated creatine phosphokinase levels. Two members of a family known to be susceptible to malignant hyperpyrexia. South African Medical Journal, 48, 640-642.

Isaacs, H., and Heffron, J. J. A. (1975a). Continuous muscle fibre activity. Cured. Further studies. Journal of Neurology, Neurosurgery, and Psychiatry, 37, 1231-1235.

Isaacs, H., and Heffron, J. J. A. (1975b). Morphological and biochemical defects in muscles of human carriers of the malignant hyperthermia syndrome. British Journal of Anaesthesia, 47, 475 .

Kark, R. A. P., Weinbach, E. C., Blass, J. P., and Engel, W. K. (1973). Oxidative metabolism in small samples of normal and diseased human muscle. In Clinical Studies in Myology, pp. 98-107. Edited by B. A. Kakulas. Excerpta Medica: Amsterdam.

Karpati, G., Carpenter, S., and Anderman, Fr. (1971). A new concept of childhood nemaline myopathy. Archives of Neurology (Chic.), 24, 291-304

Laudahn, G., and Heyck, H. (1965). Muskelenzym-Befunde bei der progressive Muskeldystrophie. In Myopathien, p. 165. Edited by R. Beckmann. Thieme: Stuttgart.

Lilienthal, J. L., Jr, Zierler, K L., Folk, B. P., Buka, R., and Riley, M. J. (1950). A reference base and system for analysis of muscle constituents. Journal of Biological Chemistry, 182, 501-508.
Lowry, O. M., Rosebrough, N. J., Farr, A. L., and Randall, R. J. (1951). Protein measurement with the folin phenol reagent. Journal of Biological Chemistry, 193, 265-275.

Margreth, A. Salviati, G., Di Mauro, S., and Turati, G. (1972). Early biochemical consequences of denervation in fast and slow skeletal muscles and their relationship to neural control over muscle differentiation. Biochemical Journal, 126, 1099-1110.

Mittelbach, F., and Pongratz, D. (1968). Klinische, histologische und histochemische Untersuchungen uber einen Fall von Central Core Disease (Zentralfibrillen-Myopathie). Deutsche Zeitshrift für unde Nervenheilk, 194, 232242.

Samaha, F. J., and Gergely, J. (1969). Biochemical abnormalities of the sarcoplasmic reticulum in muscular dystrophy. New England Journal of Medicine, 280, 184-188.

Shafiq, S. A., Goryckl, M. A., Asiedu, S. A., and Milhorat, A. T. (1969). Tenotomy. Effect on the fine structure of the soleus of the rat. Archives of Neurology (Chic.), 20, 625633.

Shy, M. G., and Magee, K. R. (1956). A new congenital non-progressive myopathy. Brain, 79, 610-621.

Streter, F. A. (1969). Temperature, pH and seasonal dependence of Ca-uptake and ATPase activity of white and red muscle microsomes. Archives of Biochemistry and Biophysics, 134, 25-33.

Telerman-Toppet, N., Gerard, S. M., and Coërs, C. (1973). Central core disease. A study of clinically unaffected muscle. Journal of the Neurological Sciences, 19, 207-223 